\title{
Risk Factors for Spontaneous Abortion
}

\author{
FABIO PARAZZINI,* LUCA BOCCIOLONE*,**, LUIGI FEDELE* *, EVA NEGRI*, CARLO LA VECCHIA*,t, \\ AND BARBARA ACAIA**
}

Parazzini F (Istituto di Ricerche Farmacologiche 'Mario Negri', Via Eritrea 62, 20157 Milano, Italy), Bocciolone L, Fedele L, Negri E, La Vecchia C and Acaia B. Risk factors for spontaneous abortion. Internationa/ Journa/ of Epidemiology 1991, 20: 157-161.

A case-control study was conducted to evaluate risk factors for spontaneous abortions. Cases were 94 women with two or more unexplained miscarriages (after exclusion of genetic, endocrine and Müllerian factors) and no term pregnancy, controls were 176 women admitted for normal delivery to the same clinic where cases were identified. Questions were asked about personal characteristics and habits, and gynaecological history. A family history of recurrent miscarriage was more common among women with spontaneous miscarriages than among the controls ( 13 cases versus 8 controls, relative risk $(R R)=3.2,95 \%$ confidence interval $(C l)=1.3-8.1)$. Compared to women whose menarche occurred at age 11 or younger, the RRs were 0.8 when menarche occurred at age 12-13 and 0.5 at age 14 or more: this trend in risk was statistically significant. Compared with never smokers, current smokers had about a $40 \%$ increased risk of miscarriage and the risk increased with number of cigarettes per day. No association emerged with sociodemographic characteristics (e.g. education, marital status, age of the partner), reproductive history (age at first pregnancy), type of contraceptive used and other general lifestyle habits (e.g. alcohol or coffee consumption).

Characteristics of women with unexplained recurrent miscarriages are poorly understood. Various factors, such as low socioeconomic status, ${ }^{1,2}$ specific occupation (i.e. anaesthesiologist, laboratory worker) ${ }^{3-5}$ smoking habits, ${ }^{6.7}$ methylxanthine or alcohol consumption ${ }^{8-11}$ and early age at menarche ${ }^{12-16}$ have been associated with an increased risk of early abortion, but epidemiological evidence is scanty and controversial.

Paternal occupation, general environmental exposures and smoking habits have been shown to impair the number, motility or morphological features of spermatozoa ${ }^{6.17}$ suggesting that male factors may be relevant in early fetal loss.

We considered the relation between general characteristics, various environmental factors and the risk of spontaneous abortion using data from a case-control study conducted in Northern Italy.

\section{SUBJECTS AND METHODS}

Between January 1987 and June 1988, trained inter-

\footnotetext{
'Istituto di Ricerche Farmacologiche 'Mario Negri', Via Eritrea 62, 20157 Milano, Italy.

- Prima Clinica Ostetrica-Ginecologica, Università di Milano, 20122 Milano, Italy.

IInstitut universitaire de medicine sociale et préventive, 1005, Lausanne, Switzerland.

Correspondence to: Fabio Parazzini, Istituto di Ricerctie Farmacologiche 'Mario Negri', Via Eritrea 62, 20157 Milano, Italy.
}

viewers identified and questioned cases and controls using a standard questionnaire. ${ }^{18}$ Cases were women who had two or more 'unexplained' miscarriages before three months of gestation and without full-term pregnancies, admitted or referred during the study period at the outpatient fertility clinic of the First Obstetric and Gynecology Clinic of the University of Milan. All women were normal at standard medical examination which included hysterosalpingogram, luteal phase endometrial biopsy, glucose tolerance test, hormonal profile (three progesterone and prolactin assays in the luteal phase plus one T3, T4, TSH and FTI assay) and determination of karyotype from peripheral leukocytes of both partners. Women with repeated miscarriages and no previous term pregnancy were identified as cases under the assumption that any potential risks factor for spontaneous abortion should be more evident in women with recurrent ones. A total of 94 cases, aged 25-39 years (median age 32) met these criteria; 67 women reported two miscarriages, 20 three, and seven four or more. Women admitted for normal delivery on randomly selected days to the same University Clinic were chosen as controls. To better distinguish potential risk factors, women were specifically excluded if they reported a history of one or more spontaneous abortions. A total of 176 women aged 24-39 years (median age 29) were interviewed. The 
distribution of cases and controls according to age and parity of controls is shown in Table 1.

Information was collected on personal characteristics and habits, gynaecological and obstetric data and smoking habits at diagnosis of pregnancy (last miscarriage for cases, index pregnancy for controls). Information on occurrence of spontaneous abortion in maternal first-degree relatives and maternal number of sisters was also obtained. Questions on alcohol, coffee consumption and smoking included consumption or smoking during the last miscarrying pregnancy for cases and in the first trimester of the index pregnancy for controls.

\section{Data Analysis}

Odds ratios (as estimators of relative risks, RR), together with their $95 \%$ confidence intervals $(\mathrm{CI})$, were computed ${ }^{19}$ and, when appropriate tested for trend. ${ }^{20}$ Potential confounding factors were controlled individually using stratification and the Mantel-Haenszel procedure. ${ }^{21}$ However, since adjustments for these factors did not materially change most of the relative risk, estimates adjusted for age only were chosen for presentation.

\section{RESULTS}

Table 2 presents the distribution of cases and controls according to selected socio-demographic and reproductive characteristics, contraception histories and general lifestyle habits found in this study to be not significantly associated with the risk of recurrent miscarriage. Education, marital status, body mass index, contraception, age at first pregnancy and alcohol consumption showed no significant relationship with spontaneous recurrent miscarriage. Coffee drinkers also were not significantly elevated risk ( $R R$ coffee drinkers versus non-drinkers $=1.4,95 \% \mathrm{CI}=0.7-2.6$ ). Paternal age tended to be higher in cases than in controls, but the relative risks adjusted for maternal age

TABle 1 Distribution of 94 cases of recurrem miscarriage and 176 controls according to age and parity of controls. Milan, Italy. 1987-88

\begin{tabular}{lccccc}
\hline & \multicolumn{2}{c}{ Cases } & & \multicolumn{2}{c}{ Controls } \\
\cline { 2 - 3 } \cline { 5 - 6 } & No. & $(\%)$ & & No. & $(\%)$ \\
\hline Age (years) & & & & & \\
$<30$ & 41 & $(44)$ & & 101 & $(57)$ \\
$30-34$ & 35 & $(37)$ & 55 & $(31)$ \\
$\geq 35$ & 18 & $(19)$ & 20 & $(11)$ \\
Parity & & & & & \\
0 & 94 & $(100)$ & & $92^{*}$ & $(52)$ \\
1 & - & - & 66 & $(38)$ \\
$\geq 2$ & - & - & 18 & $(10)$ \\
\hline
\end{tabular}

"Index pregnancy is not included. were close to unity and the trend in risk not statistically significant.

The relationship between recurrent miscarriages and maternal family history of spontaneous abortions is set out in Table 3. A family history of recurrent miscarriages was more common among women with spontaneous abortions than controls, being reported in 12 cases and eight controls. The corresponding RR was $3.2,(95 \% \mathrm{CI}=1.3-8.1)$

Table 4 presents the relationship between age at menarche and spontaneous miscarriages. Relative to women whose menarche occurred at age 11 or younger, the RR were $0.8(95 \% \mathrm{CI}=0.4-1.4)$ when menarche occurred at age 12 or 13 and $\cap 5(95 \%$

TABLE 2 Distribution of 94 cases of recurrent miscarriage and 176 controls according to demographic, reproductive and contraceptive history and lifestyle habits. Milan, Italy. 1987-88

Relative risk*

Cases Controls (95\% confidence interval)

\begin{tabular}{|c|c|c|c|}
\hline \multicolumn{4}{|l|}{ Education (years) } \\
\hline$<7$ & 7 & 14 & $1 \dagger$ \\
\hline $7-11$ & 29 & 63 & $0.9(0.3-2.4)$ \\
\hline \multirow[t]{2}{*}{$\geq 12$} & 58 & 99 & $1.2(0.5-2.9)$ \\
\hline & & & $p$ trend $=n s$ \\
\hline \multicolumn{4}{|l|}{ Marital status } \\
\hline Never married & 2 & 3 & $1+$ \\
\hline Ever married & 92 & 173 & $1.3(0.2-7.5)$ \\
\hline \multicolumn{4}{|l|}{ Patemal age } \\
\hline$<30$ & 20 & 50 & $1 \dagger$ \\
\hline $30-34$ & 37 & 78 & $1.2(0.6-2.4)$ \\
\hline $35-39$ & 23 & 33 & $1.4(0.5-3.7)$ \\
\hline \multirow[t]{2}{*}{$\geq 40$} & 14 & 15 & $1.0(0.2-4.6)$ \\
\hline & & & $p$ trend $=\mathrm{ns}$ \\
\hline \multicolumn{4}{|c|}{ Age at first pregnancy } \\
\hline$<25$ & 35 & 64 & $1 \dagger$ \\
\hline $25-29$ & 39 & 85 & $0.8(0.5-1.4)$ \\
\hline \multirow[t]{2}{*}{$\geq 30$} & 20 & 27 & $1.2(0.5-3.2)$ \\
\hline & & & $p$ trend $=n s$ \\
\hline \multicolumn{4}{|c|}{ Oral contraceptive use } \\
\hline Never & 64 & 123 & $1+$ \\
\hline Ever & 30 & 53 & $1.1(0.7-1.7)$ \\
\hline \multicolumn{4}{|l|}{ IUD use } \\
\hline Never & 85 & 162 & $1+$ \\
\hline Ever & 9 & 14 & $1.2(0.5-3.0)$ \\
\hline \multicolumn{4}{|c|}{ Coffee consumption } \\
\hline No & 16 & 42 & $1+$ \\
\hline Yes & 78 & 134 & $1.4(0.7-2.6)$ \\
\hline \multicolumn{4}{|c|}{ Alcohol consumption } \\
\hline No & $37 \ddagger$ & 69 & $1+$ \\
\hline Yes & 55 & 107 & $0.9(0.6-1.5)$ \\
\hline \multicolumn{4}{|c|}{ Body mass index $\left(\mathrm{kg} / \mathrm{m}^{2}\right)$} \\
\hline$<20$ & 29 & 62 & $1+$ \\
\hline $20-22.5$ & 34 & 54 & $1.3(0.7-2.5)$ \\
\hline \multirow[t]{2}{*}{$>22.5$} & 31 & 60 & $1.1(0.6-2.0)$ \\
\hline & & & ptrend $=$ ns \\
\hline
\end{tabular}

- Adjusted for age.

tReference category.

ns = not significant.

$¥$ The sum does not add up to the total because of missing values. 
TABLE 3 Distribution of 94 cases of recurrent miscarriages and 176 controls according to maternal family history of spontaneous abortions. Milan, Laly, 1987-88

\begin{tabular}{lrrc}
\hline & Cases & Controls & $\begin{array}{c}\text { Relative risk* } \\
(95 \% \text { confidence interval) }\end{array}$ \\
\hline $\begin{array}{l}\text { Matemal family history of } \\
\text { spontaneous abortions }\end{array}$ & & \\
No & 82 & 168 & $1+$ \\
Yes & 12 & 8 & $3.2(1.3-8.1)$ \\
\hline
\end{tabular}

*Adjusted for age.

tReference category.

$\mathrm{CI}=0.2-1.0)$ at age 14 or more. This trend in risk was statistically significant.

Smoking habits are considered in Table 5. Compared with never smokers, current smokers had an about $40 \%$ increased risk of recurrent abortion ( $\mathrm{RR}=1.495 \% \mathrm{CI}=0.8-2.9)$ and the risk increased with number of cigarettes per day the trend in risk being statistically significant.

\section{DISCUSSION}

Various areas of potential interest emerged from this exploratory study of causes of unexplained miscarriages. Women with spontaneous abortion had a family history of fetal wastage, were more frequently cigarette smokers and had early age at menarche. No association emerged with indicators of social class, marital status, paternal age, body mass index and alcohol and coffee consumption.

Various potential sources of bias should be considered in the interpretation of these findings. The choice of women who delivered only normal babies as controls seemed the most appropriate in terms of comparability with cases, since it excluded infertile women and patients with previous abortion who may share similar characteristics with cases. Other sources of selection bias were considered not important in this study. Controls were identified over the same period on selected days and in the same institution as cases, and participation rate was almost complete.

Recall bias should be taken into account in the inter-

TABLE 4 Distribution of 94 cases of recurrent miscarriage and 176 controls according to age at menarche. Milan, Laly, 1987-88

\begin{tabular}{lccc}
\hline & Cases & Controls & $\begin{array}{c}\text { Relative risk" } \\
(95 \% \text { confidence interval) }\end{array}$ \\
\hline $\begin{array}{l}\text { Age at menarche } \\
<12\end{array}$ & 31 & 46 & $1+$ \\
$12-13$ & 52 & 91 & $0.8(0.4-1.4)$ \\
$>13$ & 11 & 39 & $0.5(0.2-1.0)$ \\
& & & $p$ trend $=0.04$ \\
\hline
\end{tabular}

*Adjusted for age.

tReference category. pretation of the positive association between family history of recurrent early fetal loss and spontaneous miscarriages, because cases are probably more aware of obstetric problems. However, no association emerged with family history or other obstetric problems, e.g. late fetal loss or ectopic pregnancy (data not shown). It is thus conceivable that some family/genetic component may play a role in the aetiology of abortion, even though clinically evident genetic anomalies were ruled out by the determination of karyotype from peripheral leukocytes.

A positive association emerged between early repeated miscarriages and smoking habits. The risk estimates did not appreciably change after adjustment for potential confounding factors such as education and occupation. The harmful effects of cigarette smoking in pregnancy are well recognized.$^{6,7}$ An increased rate of spontaneous abortions in smokers has been reported in several prospective and retrospective studies, with relative risks ranging from 1.2 to $1.8 .^{6.11 .22-24} \mathrm{In}$ biological terms, smoking can cause fetal loss by decreasing uteroplacental perfusion and leading to fetal hypoxia. Morphological changes in the placental vasculation causing chronic ischaemia and chronic hypoxia have been observed in smokers. ${ }^{25}$ These findings have been associated with the many pathophysiological adverse effects of smoking on reproduction, ranging from early fetal loss to low birthweight or preterm birth. ${ }^{6}$

This study also highlighted the relationship between early age at menarche and increased risk of miscarriage. Several other studies on different populations have reported an inverse relationship between age at menarche and risk of spontaneous abortions. These findings were, however, largely controversial ${ }^{12-16}$ and have been criticized because they are based on interviews with old women, whose recall of age at menarche may well be imprecise. ${ }^{26}$ Recall bias should not be a

TABLE 5 Distribution of 94 cases of recurrent miscarriage and 176 controts according to smoking habits. Milan, thaly, 1987-88

\begin{tabular}{lccc}
\hline & Cases & Controls & $\begin{array}{c}\text { Relative risk* } \\
(95 \% \text { confidence interval) }\end{array}$ \\
\hline $\begin{array}{l}\text { Never smokers } \\
\text { Current smokers }\end{array}$ & 44 & 98 & $1+$ \\
$\begin{array}{l}\text { (no. cigarettes/day) } \\
\quad 1-9\end{array}$ & 18 & 32 & $1.3(0.6-2.5)$ \\
$\quad 10$ & 17 & 20 & $1.6(0.7-3.2)$ \\
Exsmokers $\neq$ & 15 & 26 & $1.1(0.4-2.5)$ \\
& & & p trend $=0.048$ \\
\hline
\end{tabular}

*Adjusted for age.

tReference category.

¥Exsmokers were defined as women who quit smoking more than one year before the diagnosis of the index pregnancy. SExsmokers excluded. 
major problem in the present study since more than $75 \%$ of cases and controls were below age 35 , and it is unlikely that case or control status influenced reporting of age at menarche. Likewise, adjustment for major potential confounding factors (including socioeconomic status and body mass index) did not appreciably change the estimated RRs. It is still difficult to explain this association, although early maturation or the occurrence of menses before complete maturation/ growth of uterus may, in itself, represent a disadvantage for reproduction.

Some negative findings should be briefly discussed. No association emerged in this study between education and risk of spontaneous miscarriage. The risk of spontaneous abortion increased from higher to lower social class in a study conducted in the early 1970 s in Finland,' but was not found to be associated with socioeconomic class in a more recent analysis conducted on 700 women in Denmark. ${ }^{2}$

With regard to alcohol and coffee consumption, no statistically significant association emerged with the risk of recurrent miscarriages, although cases were more frequently coffee drinkers. These findings are consistent with most (but not all) available epidemiological data. For example, no association between alcohol consumption and first trimester miscarriages emerged in studies conducted in Finland ${ }^{27}$ or California, ${ }^{11}$ although an approximately $25 \%$ increased risk of spontaneous miscarriages in women drinking alcoholic beverages twice a week or more was found in a casecontrol study conducted in the $\mathrm{US}^{10}$ (see ${ }^{18}$ for a detailed discussion).

Data on the relationship between coffee drinking and miscarriage are scanty and not completely consistent. For example no relationship between caffeine consumption and spontaneous abortion emerged in a retrospective cohort study on a Mormon population, ${ }^{28}$ but an elevated late spontaneous abortion risk of about $70 \%$ was observed in heavy caffeine users in a prospective study of more than 3000 women conducted in the US. This finding was however of borderline statistical significance. ${ }^{29}$ In consideration of the reported association between caffeine consumption in pregnancy and low birthweight, and its potential teratogenic effect, ${ }^{8}$ coffee consumption in pregnancy represents an important topic for epidemiological and biological studies on reproduction towards which this study has provided some (however inconclusive) additional data.

\section{ACKNOWLEDGEMENTS}

This work was conducted within the framework of the CNR (National Research Council, Rome, Italy) Applied Project 'Risk Factors for Diseases' and of the
Program on Clinical Pharmacology, 'Drug Use Monitoring'.

We wish to thank Ms Judy Baggott, Ivana Garimoldi and Antonietta Di Bitetto for editorial assistance.

\section{REFERENCES}

'Hemminki K, Niemi M L, Saloniemi I, Vainio H, Hemminki E. Spontancous abortions by occupation and social class in Finland. Int J Epidemiol 1980; 9: 149-53.

${ }^{2}$ Rachootin P, Olsen J. Prevalence and socioeconomic correlates of subfecundity and spontaneous abortion in Denmark. Int $J$ Epidemiol 1982; 11: 245-9.

${ }^{3}$ Lee W R, McCloy E C. Reproduction and work. Br Med J/Clin Res/ 1986; 293: 1521 .

4 Tomlin P J. Health problems of anesthetists and their families in the West Midlands. Br Med J /Clin Res/ 1979; 1: 779-84.

${ }^{3}$ Heidam L Z. Spontaneous abortions among laboratory workers; a follow-up study. I Epidemiol Community Health 1984; 38: $36-41$.

- Stillman R J, Rosenberg M J, Sachs B P. Smoking and reproduction. Fertil Steril 1986; 46: 545-66.

${ }^{7}$ Office on Smoking and Health. Pregnancy and infant health. In: The Health Consequences of Smoking for Women. A report of the surgeon General. Office of the Assistant Secretary for Health 1980; pp. 189-249.

' Heller $J$. What do we know about the risks of caffeine consumption in pregnancy? $\mathrm{Br} J$ Addict 1987; 82: 885-9.

' Linn S, Schoenbaum S C, Monson R R, Rosner B, Stubblefield P G, Ryan K J. No association between coffee consumption and adverse outcomes of pregnancy. $N$ Engl J Med 1982; 306: 141-5.

${ }^{10}$ Kline J, Shrout P, Stein Z, Susser M, Warburton D. Drinking during pregnancy and spontaneous abortion. Lancer 1980; 2: 176-80.

${ }^{11}$ Harlap S, Shiono P H. Alcohol, smoking and incidence of spontaneous abortions in the first and second trimester. Lancet 1980; 2: $173-6$.

12 Liestol K. Menarcheal age and spontaneous abortion: a causal connection? Am J Epidemiol 1980; 111: 753-8.

${ }^{4}$ Casagrande J T, Pike M C, Henderson B E. Re: Menarcheal age and spontaneous abortion: a causal connection? Am J Epidemiol 1982; 115 : 481-3.

14 Majaux M J, Spira A, Schwartz D. Re: Menarcheal age and spontaneous abortion: a causal connection? Am J Epidemiol 1983; 117: 377-8.

${ }^{3}$ Martin E J, Brinton L A, Hoover R. Menarcheal age and miscarriage. Am J Epidemiol 1983; 117: 1634-6.

${ }^{16}$ Sandler D P, Wilcox A J, Horney L F. Age at menarehe and subsequent reproductive events. Am J Epidemiol 1984; 119: 765-74.

${ }^{17}$ Lindbohm M L, Hemminki K, Kyyronen P. Parental occupation exposure and spontaneous abortions in Finland. Am J Epidemiol 1984; 120 : $370-8$.

4. Parazzini F, Bocciolone L, La Vecchia C, Negri E, Fedele L. Maternal and paternal moderate daily alcohol consumption and unexplained miscarriages. Br J Obstet Gynecol 1990; 97: 618-22.

Miettinen $O$. Estimability and estimation in case-referent studies. Am J Epidemiol 1976; 103: 226-35.

D Mantel N. Chi-square tests with one degree of freedom, extensions of the Mantel-Haenszel procedure. J Am Stat Assoc 1963; 58: 690-700.

${ }^{21}$ Mantel N, Haenszel W. Statistical aspects of the analysis of data from retrospective studies of disease. JNCl 1959; 22: 719-48.

${ }^{2}$ Kline J, Stein Z A, Susser M, Warburton D. Smoking: a risk factor for spontaneous abortion. N Engl J Med 1977; 297: 793-6. 
${ }^{\text {D }}$ Himmelberger D U, Brown B W Jr, Cohen E N. Cigarette smoking during pregnancy and the occurrence of spontaneous abortion and congenital abnormality. Am J Epidemiol 1978; $108: 470-9$.

${ }^{24}$ Hemminki K, Mutanen P, Saloniemi I. Smoking and the occurrence of malformations and spontaneous abortions: multivariate analysis. Am J Obstet Gynecol 1983; 145: 61-6.

${ }^{8}$ Van der Veen F, Fox $H$. The effects of cigarette smoking on the human placenta: a light and electron microscopic study. Placenta $1982 ; 3: 243-6$.

${ }^{\varpi}$ Bean J A, Leeper J D, Wallace R B, Sherman B M, Jagger H. Variations in the reporting of menstrual histories. Am $J$ Epidemiol 1979; 109: 181-5.
${ }^{\pi}$ Halmesmaki E, Valimaki M, Roine R, Ylikahri R, Ylikorkata $\mathbf{O}$. Maternal and patemal alcohol consumption and miscarriage. Br J Obstet Gynecol 1980; 96: 188-91.

* Weatherbee P, Osen L, Lodge J R. Caffeine and pregnancy: a retrospective study. Post-graduate Medicine 1977; 62: 64-9.

- Srisuphan W, Bracken M B. Caffeine consumption during pregnancy and association with late spontaneous abortion. Am $J$ Obstet Gynecol 1986; 154: 14-20.

(Revised version received August 1990) 